Rischmoller, L., Reed, D., Khanzode, A., and Fischer, M.(2018). "Integration Enabled by Virtual Design and Construction as a Lean Implementation Strategy" In: Proc. 26th Annual Conference of the International. Group for Lean Construction (IGLC), González, V.A. (ed.), Chennai, India, pp. 240-249. DOI: https://doi.org/10.24928/2018/0521. Available at: www.iglc.net.

\title{
INTEGRATION ENABLED BY VIRTUAL DESIGN \& CONSTRUCTION AS A LEAN IMPLEMENTATION STRATEGY
}

\author{
Leonardo Rischmoller ${ }^{1}$, Dean Reed ${ }^{2}$, Atul Khanzode ${ }^{3}$ and Martin Fischer ${ }^{4}$
}

\begin{abstract}
This theory paper probes the intersections of Lean, Mass Production and conventional Construction, Lean Construction, the Simple Framework for Integrating Project Delivery model, and Virtual Design and Construction (VDC). The authors argue that Toyota recognized that integration was necessary to achieve the goal of global optimization in design and production and that this imperative confronts Lean Construction today. They briefly describe the Simple Framework for Integrating Project Delivery as a system model to achieve the high level of integration required to deliver a valuable, highperforming building. Then they focus on how VDC fits within and enables the Simple Framework model, explaining each element of VDC and how project teams can leverage it to consistently deliver high-performing buildings.
\end{abstract}

\section{KEYWORDS}

Theory, production, Lean Construction, Simple Framework for Integrating Project Delivery, Virtual Design \&Construction

\section{INTRODUCTION}

\section{LEAN PRODUCTION ORIGINSAND THE CONSTRUCTION INDUSTRY}

On Ford's mass-production line, the assembler had only one task and did not understand what the workers on either side of him were doing. Speaking the same language as his fellow assemblers or the foreman was not required for the success of Ford's system (Womack et al. 1990). There are many construction project sites in which contractors and

1 Business Analyst, DPR Construction, 1450 Veterans Boulevard, Redwood City, CA 94063, USA, LeonardoR@dpr.com

2 Lean/Integration Advocate, DPR Construction, 1450 Veterans Boulevard, Redwood City, CA 94063, USA, DeanR@dpr.com

3 Technology and Innovation Leader, DPR Construction, 1450 Veterans Boulevard, Redwood City, CA 94063, USA, AtulK@dpr.com

4 Kumagai Professor of Engineering and Professor of Civil and Environmental Engineering and Director, Center for Integrated Facility Engineering (CIFE), Stanford University, Stanford, CA, fischer@stanford.edu 
subcontractors do not communicate much better than Ford's mass production assemblers. Furthermore, this fragmented scenario can also be observed to a big extent during the architecture and engineering hours spent designing a new construction project.

While at Ford's plants, the industrial engineer had to think about how all the parts came together as integrated systems, and just what each assembler should do within integrated processes, currently, to a big extent Project Managers and Superintendents play the roles of industrial engineers at construction jobsites, and also during project design stages.

\section{LEAN PRODUCTION AND INTEGRATION}

Integration was not explicitly mentioned in The Machine that Changed the World, when Jim Womack, and his co-authors argued that the Toyota Production System was really a new "lean" approach to production in which the work of all suppliers was integrated so that value flowed at the pull of the customer (Womack et al.1990). Integration was and is necessary for Toyota to achieve the "global optimization" required to deliver the value their customers were and are seeking. This is a significant leap beyond "local optimization "where individual contributors seek better outcomes for themselves, often at the expense of others (Forbes \&Ahmed 2010).

"Lean" uses less of everything compared with mass production: half the human effort in the factory, much less manufacturing space, less investment in tools, many fewer engineering hours to develop a new product in half the time, far less than half the needed inventory on site, and near zero defects; all while producing a greater and ever-growing variety of products. Womack stated that this "less-than" approach calls for different management skills and applying these creatively in a team setting rather than in a rigid hierarchy, with a key objective of lean production to push responsibility far down the organizational ladder(Womack et al. 1990). This resembles the integrated organization idea introduced by Tillmann, Ballard, Tzortzopolous and Formoso (Tillman et al. 2012).

Fischer, Ashcraft, Reed and Khanzode went beyond Tillmann and her co-authors' idea of an integrated organization to the bigger idea of a system model, where each element depends on all the others and can consistently produce a high-performing facility(Fischer et al. 2014; Fischer et al. 2017).

\section{INTEGRATION AS A LEAN STRATEGY}

This paper proposes that in addition to the lean construction goal to maximize value and to reduce waste in order to "redefine perfection in construction" (Ballard \&Howell 1998; Salem et al. 2005), integration, in this case enabled by Virtual Design \& Construction, should be seen as a lean strategy, just as supply-chain integration was originally within the Toyota Production System.

\section{THE SIMPLE FRAMEWORK FOR INTEGRATION}

Building on the American Institute of Architects (AIA) "Integrated Project Delivery: A Guide" (2007) and on the organization / commercial terms / operating system model of IPD adopted by the Lean Construction Institute (Thomsen et al. 2009),Fischer, Ashcraft, Reed and Khanzode have explained that process knowledge, organization and 
information must be integrated to produce the highly integrated systems necessary for a high-performing building, which they define as usable, buildable, operable and sustainable. "A high-performing building can only be achieved through a building with integrated building systems, which can only be produced through an integrated process, which depends on an integrated team with the right people, which need integrated information, to function effectively and efficiently. Simulation and visualization are the primary ways in which BIM informs the integrated team. Collaboration and co-location are the primary ways to allow the integrated team to integrate processes. Production management methods enable the productive design, fabrication, and construction of the integrated building system. Outcome metrics define the performance of the building and validate the integrated building system. All of this is supported by the appropriate agreement or framework (Fischer et al. 2017; Ashcraft 2014)." Figure 1 shows these relationships in what Fischer, Ashcraft, Reed and Khanzode call "The Simple Framework for Integrating Project Delivery (Fischer et al. 2014)."

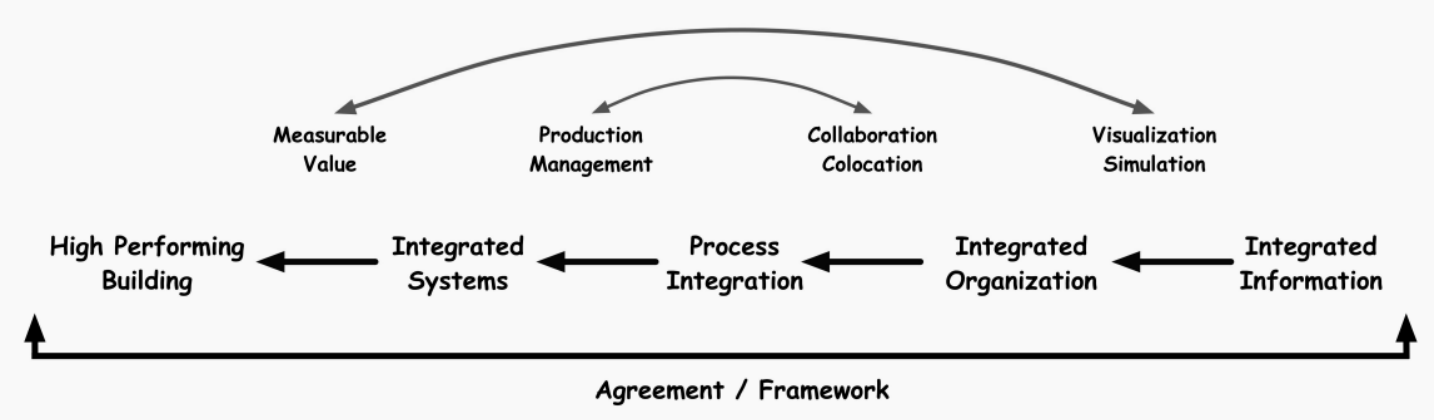

Figure 1: Simple Framework for Integrating Project Delivery(Fischer et al. 2017)

\section{VIRTUAL DESIGN AND CONSTRUCTION (VDC)}

\section{VDC AS AN ENABLER OF INTEGRATION}

Virtual Design and Construction or VDC was developed through research over the last two decades at Stanford University's Center for Integrated Facility Engineering (CIFE) (Khanzode et al. 2006; Kunz \& Fischer 2012). CIFE defines Virtual Design \&Construction (VDC) as "the use of multi-disciplinary performance models of designconstruction projects, including the Product (i.e., facilities), Work Processes and Organization of the design - construction - operation team in order to support business objectives."

Based on their own direct observations and reports from practitioners, the authors believe that VDC is a very effective method for project teams to integrate their knowledge and create the information they need to integrate building systems. VDC is the main enabler of the Simple Framework model. The following are the main components of VDC. 


\section{BIM+}

Building Information Modeling (BIM) has proven to be very useful for validating spatial relationships of components and systems performance (Hardin \&McCool 2015). Combining BIM with time to produce 4D models, with cost data to estimate cost, or with lighting and energy data is what VDC researchers call "BIM+."

Michael Schrage, wrote in 2000 about the rise and benefits of digital modeling media to create prototypes and simulations in companies like Toyota, Chrysler, Boeing, Hewlett Packard, Caterpillar, GE, etc. and how the value of a prototype arises from how much people learn as they create and test models collaboratively over time.(Schrage 2000).Project team members have observed this dynamic with BIM. Like Schrage, VDC states that the value of BIM resides less in the models themselves than in the interactions they invite. Building Information Models often reveal choices people must make, requiring trade-offs not apparent to them initially. Models don't solve business problems, any more than mathematics solves equations. How models are used determines whether and how problems are solved (Schrage2000).

From the VDC perspective the proper question is not "How will this simulation or model solve the problem?" but rather "How will this simulation or model be used by the project team to solve the problem?" The authors believe there has been too much focus on the quality of the model and not enough on how using the model will change organization's behavior.

Perfectly good models ignored because no one cares to work with them are underutilized investments that create only marginal value for the enterprise. If models can be made more accessible through techniques of simplification and visualization, without undermining their validity, they stand a better chance of being used by designers and builders rather than a relatively small group of BIM specialists (Rischmoller et al. 2017).

The proliferation of BIM tools can dramatically transform how the construction industry creates value for its customers. A corollary hypothesis is that an organization's ability to create value now depends on its ability to use these tools effectively. From the VDC perspective, the business issue here is not only the challenge of better information or more effective knowledge management. It is how does the project organization's way of modelling improve its ability to create value?

\section{Project Production Management (PPM)}

PPM is simply the application of operations science to projects by viewing them as temporary production systems. PPM focuses on organization and control of work activities in a project. It provides deeper quantitative and predictive theory on the achievable limits and design of work activities, validated by practice in several settings. The ability to model and simulate work activities to establish the limits of what is and is not theoretically achievable, as well as the ability to infer design criteria to optimize parameters such as throughput, work-in-process, cycle time and use of capacity lead directly to an improvement in cost, schedule and scope performance on projects (Shenoy 2017).

While Lean Construction is not a subset of Project Production Management, neither is Project Production Management a subset of Lean Construction (Shenoy2017), Lean 
Construction, as envisaged in 1993, had several similarities with Project Production Management as defined by the Project Production Institute (PPI). Figure 2 below illustrates the historical evolution of PPM and Lean, emphasizing the operations science foundations of both PPM and Lean.

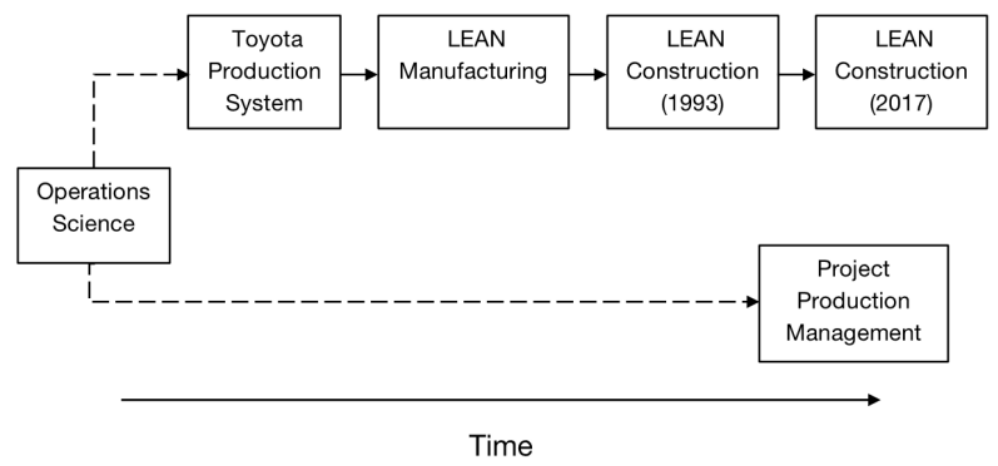

Figure 2 The Operations Science foundation underlying Lean and Project Production Management (Shenoy 2017)

However, over the ensuing 25 years, the concept of Lean Construction and that of PPM, as espoused by the PPI when founded in 2013, followed diverging paths. The core difference can be understood by asking how "system" is defined in "project delivery system" for Lean Construction versus PPM. Lean Construction increasingly focused on human factors, primarily project governance and organization of project stakeholders, whereas Project Production Management focuses on the configuration and organization of the physical work tasks that get performed in a project. Lean Construction has expanded its framework to cover issues of project governance such as contracts, integrated forms of agreement and organization of stakeholders, such as in the Lean Project Delivery System (Seed 2010).

VDC combines the focus on physical work activities in PPM and the human focus of present-day Lean Construction, and enhances both through the introduction of Integrated Concurrent Engineering.

\section{Integrated Concurrent Engineering}

Integrated Concurrent Engineering (ICE) is an approach that breaks the decades-long approach of working in isolation and coming together in meetings to report progress and problems. ICE combines engineering analysis and team communication and decisionmaking. This increases feedback within the design team, shortening design iterations and reducing wasted effort (Coffee 2006).

Based on careful observation of "Extreme Collaboration" methods by the NASA's Jet Propulsion Laboratory (JPL), CIFE faculty and researchers formalized and extended them as ICE, and then incorporated ICE into Virtual Design and Construction (Kunz \&Fischer 2012). The productivity of ICE relies on a cycle of convergence in collaborative work sessions to share information, align understandings and coordinate action, followed by divergence for further study and testing, which is repeated until solutions are found for engineering problems. Whereas traditional meetings often suffer from vague meeting 
agendas, poor participant preparation, unclear logging of decisions made, and haphazard follow-up work, ICE sessions counter these challenges with a clear agenda with explicit objectives, well-prepared participants, and active problem-solving(Fosse et al. 2017).

The term "coordination latency," defined as the elapsed time between a request for information or action and meeting that request, is offered as a unifying, intuitive, descriptive performance metric, intended to reach a near-zero value as a project design goal (Chachere et al.2004). Coordination latency is reduced dramatically during ICE sessions.

ICE sessions use Building Information Models and simulations as instruments for introspection so that participants can learn from the conversations that otherwise wouldn't take place. Precisely because organizations are communities of people and not aggregations of data, the real power of BIM utilized in ICE sessions, comes from changing behavior as participants engage with their models. The transparency introduced by visualization and simulation promotes greater openness, which often forces people to re-examine how they should interact with each other. What should be shared? How safe is it to admit confusion or failure? What are the rules of engagement? Models aren't only essential for designing product and production processes, they enable collaboration (Schrage 2000).

During ICE sessions supported by BIM and the Lean principle of flow, not only is the time to get an answer shorter, participants can ask many more questions earlier. Although further research is needed to validate this intuition, the effect of integration enabled by ICE as a key component of VDC on the timing and number of questions asked, and response latency may be significant. Figure 3 shows a simple two-by-two matrix for evaluating the effectiveness of VDC and Integrated Project Delivery (IPD) compared to traditional practice.

Effect of VDC + IPD on timing and number of questions asked and

response latency

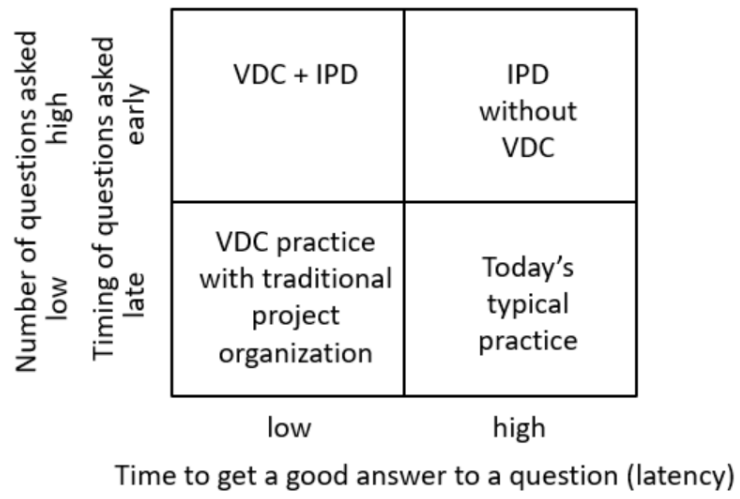

Figure 3: Questions and answers with VDC vs. traditional practice

\section{Client Goals and Project Objectives}

Many owners want to optimize use and sustainability while reducing lifecycle operating costs such as building maintenance, building operations, and business operations, along with first cost to construct. However, traditional practice focuses primarily on designing a 
building primarily for lowest construction cost and fastest delivery. Project objectives and client objectives are not aligned (Evbuomwan \& Anumba 1998; Fischer et al. 2017).

The purpose of VDC is to solve business problems. Project objectives must support client goals. If sustainability and lifecycle cost are goals, they must not be left to chance. The Simple Framework model requires project teams to determine objectives where total cost and building performance must always be considered together. The facility must be useable, buildable, operable and sustainable. Figure 4 shows the relationships between client goals and project objectives enabled by VDC within the Simple Framework model(Fischer et al. 2017).

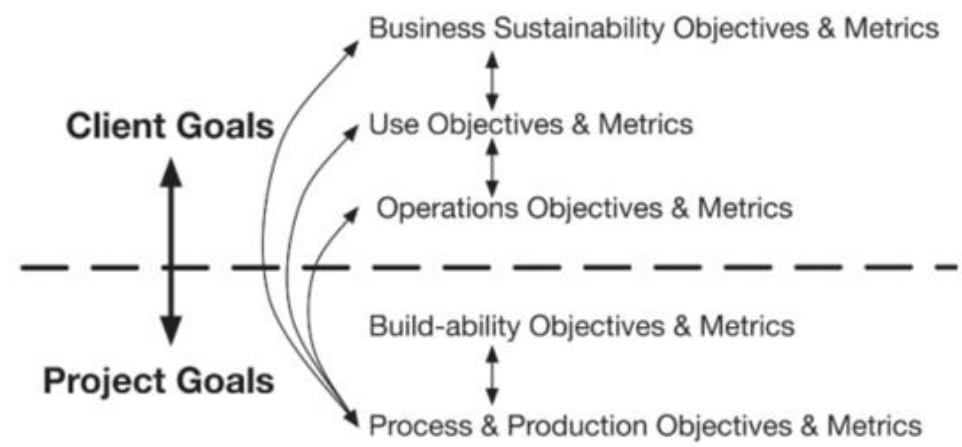

Figure 4: Client and project goals and objectives (Fischer et al. 2017)

The Simple Framework stipulates that a highly valuable building can be created when project objectives support specific, clearly defined client goals for a high-performing building. In this way VDC and Lean intersect at their common starting points of delivering the greatest possible value.

\section{Metrics}

Through measurement, a team can gain control over how to achieve the objectives of a project (Shawn et al. 2004). The project team must translate client goals into use, operation and sustainability performance metrics along with those for safety, quality, schedule and cost to measure buildability (Fischer et al. 2017; Rankin et al. 2008).

Economic objectives include metrics for first and lifecycle cost. Environmental goals include metrics like habitat availability for plant and wildlife, storm water retention capacity, carbon dioxide (CO2) emissions over the lifecycle or in a particular project phase, and similar considerations (Kent \& Becerik-Gerber 2010). Besides safety during construction, social goals may include development of human capabilities, construction workforce diversity, and community interaction and support. Some objectives can be measured while others are assessments.

VDC practice goes beyond project outcomes, which are lagging reports after the fact. The most useful metrics are leading and focused on factors team leaders believe are important such as meeting participation, number of innovations proposed, the extent of BIM use, and the number of jointly agreed quality acceptance criteria. Establishing metrics is the first order of business once project and work process objectives are decided. 


\section{VDC IS INTEGRATED}

VDC occurs when its components are part of an integrated approach rather than being used in isolation. For example, it is common to find BIM and Lean areas or departments in projects and companies. If people in these two areas or departments work in isolation from each other, we cannot say that VDC is being applied. Figure 5 shows the relationships between VDC elements, making the point that it is not enough to adopt each of its components in an isolated way. BIM+ and PPM jointly support collaboration during ICE sessions which are intended to achieve metrics aligned with project objectives supporting client goals.

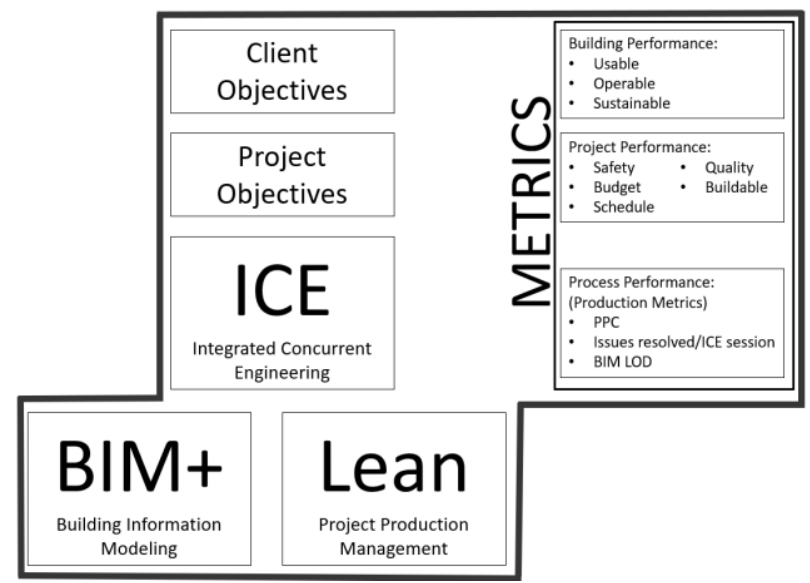

Figure 5: Virtual Design \& Construction as a set of integrated elements

\section{VDC AS ENABLER OF THE SIMPLE FRAMEWORK}

VDC functions as a subsystem enabling the integration of knowledge, organization and information required to produce the highly integrated system making-up a highperforming building. VDC is the way project teams work to deliver the value their clients are seeking. Figure 6 shows VDC as the enabling upper tier of the Simple Framework.

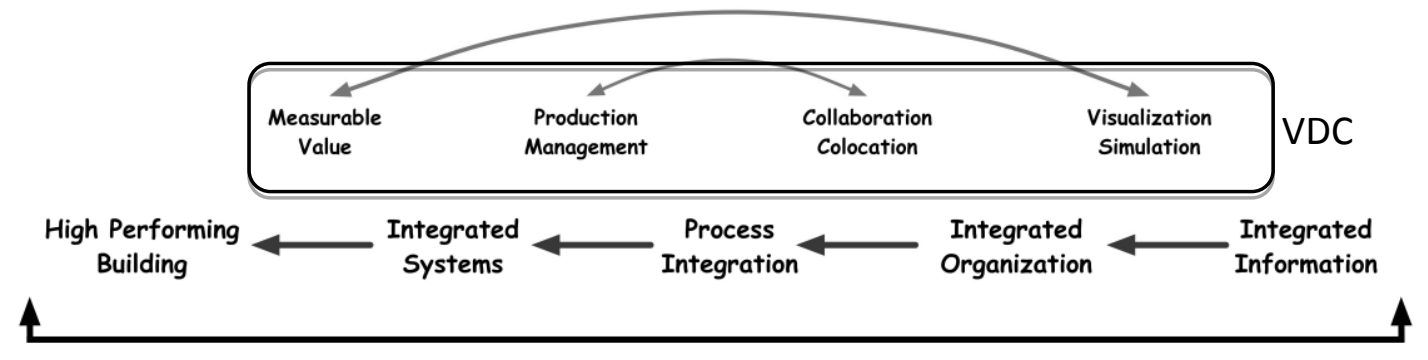

Agreement / Framework

Figure 6: VDC enabling the Simple Framework 


\section{CONCLUSIONS}

Lean is making value flow at the pull of the customer. This requires global optimization, which requires integration of the supply chain. There is no choice. The Simple Framework for Integrating Project Delivery describes four integrations required for project teams to consistently delivery high-performing buildings, defined as usable, buildable, operable and sustainable. The Simple Framework has two enablers. The first is an agreement of parties on financial terms, responsibilities, and governance that allow them to build trust, so they can collaborate for the good of the project. The second enabler is Virtual Design and Construction, which is a method for solving complex design and construction problems. VDC requires people to collaborate to reach measurable objectives they establish. It is integrative by nature and can be learned and mastered. Everything people do within the VDC framework allows them to integrate systems, processes, their organization and information so they can deliver highperforming buildings.

\section{REFERENCES}

Ashcraft, H. W. (2014). "Integrated project delivery: a prescription for an ailing industry." Const. L. Int'l, 9, 21

Ballard, G. and G. Howell (1998). "Implementing lean construction: Understanding and action". IGLC-6, Guarujá, Brazil, UFRGS.

Chachere,J., Kunz, J., and Levitt, R. (2004).“Integrated Concurrent Engineering: Grounded Theoretical Factors that Enable Radical Project Acceleration." CIFE Working Paper \#WP087.

Chachere, J., Kunz, J., and Levitt, R. (2004). "The Role of Reduced Latency in Integrated Concurrent Engineering." CIFE Working Paper \#WP087, Aug, 2004.

Coffee, T. (2006). "The Future of Integrated Concurrent Engineering in Spacecraft Design." The Lean Aerospace Initiative Working Paper Series, MIT.

Evbuomwan, N.F.O, Anumba, C.J. (1998). "An integrated framework for concurrent lifecycle design and construction." Advances in Engineering Software, 29(7-9), 587-597.

Fischer, M., Ashcraft, H., Reed, D. and Khanzode, A. (2017). Integrating Project Delivery, John Wiley \& Sons, Inc., Hoboken, NJ.

Fischer, M., Reed, D., Khanzode, A., andAshcraft, H.(2014). "A Simple Framework for Integrated Project Delivery." 22nd Annual Conf. of the Intntl. Group for Lean Construction. Oslo, Norway. 1319 - 1330.

Forbes, L. H., and Ahmed, S. M. (2010). Modern Construction: Lean Project Delivery and Integrated Practices. CRC Press, Boca Raton, FL.

Fosse, R., Ballard, G. and Fischer, M. (2017) "Virtual Design and Construction: Aligning BIM and Lean in Practice." In: LC\# 2017 Volume II - Proceedings of the 25th Annual Conference of the International Group of Lean Construction (IGLC), Walsh, K., Sacks, R., Brilakis, I. (eds.), Heraklion, Greece, pp. 499-506. DOI: (N.F.O Evbuomwan and C.J Anumba 1998)

Hardin, B. and McCool, D. (2015). BIM and Construction Management: Proven Tools, Methods, and Workflows. John Wiley \& Sons, pp 408. 
Hughes, S.W., Tippett, D. D., and Thomas, W. K. (2004). "Measuring Project Success in the Construction Industry." Engineering Management Journal, 16(3), 31-37.

Integrated Project Delivery: A Guide - AIA." (2007). <https://www.aia.org/resources/64146-integrated-project-delivery-a-guide> (May 7, 2018).

Khanzode, A., Fischer, M., Reed, M. and Ballard, G. (2006). "A guide to applying the principles of Virtual Design \& Construction (VDC) to the Lean Project Delivery Process.” CIFE Working Paper \#093, Stanford, CA.

Kent, D. C., and Becerik-Gerber, B. (2010). "Understanding Construction Industry Experience and Attitudes toward Integrated Project Delivery." Journal of Construction Engineering and Management, 136(8), 815-825.

Kunz, J. and Fischer, M. (2012)."Virtual Design and Construction; Themes, Case Studies and Implementation Suggestions.” CIFE Working Paper \#097, Version 14, Jan 2012.

Rankin, J., Fayek, A. R., Meade, G., Haas, C., and Manseau, A. (2008). "Initial metrics and pilot program results for measuring the performance of the Canadian construction industry." Canadian Journal of Civil Engineering, 35(9), 894-907.

Rischmoller, L., Dong, N., Fischer, M. and Khanzode, A. (2017).'Improving On-Site Meeting Efficiency by Using an Automated Model Breakdown Tool" In: 25th Annual Conference of the International Group for Lean Construction. Heraklion, Greece, 912 Jul 2017. pp 397-404.

Salem, O., Solomon, J., Genaidy, A., and Luegring, A. (2005). "Site Implementation and Assessment of Lean Construction Techniques." Lean Construction Journal 2 (2) 1-21.

Seed, W. R. (ed.) (2010). Transforming Design and Construction: A Framework for Change, Lean Construction Institute.

Shenoy, R.G. (2017). "A Comparison of Lean Construction with Project Production Management." Project Production Institute Journal, Volume 2.

Schrage, M. (2000), Serious Play, How the world's best companies simulate to innovate, Harvard Business School Press, Boston, Massachusetts.

Thomsen, C., Darrington, J., Dunne, D., and Lichtig, W. (2009). "Managing Integrated Project Delivery." CMAA.

Tillmann, P., Ballard, G.,Tzortzopolous, P., and Formoso, C. (2012). "How Integrated Governance Contributes to Value Generation - Insights from an IPD Case Study."20th Annual Conference of the International Group for Lean Construction San Diego, USA - 2012.

Womack, J.P., Jones, D.T., and Roos, D. (1990). The Machine That Changed the World: Based on the Massachusetts Institute of Technology 5-Million-Dollar 5-Year Study on the Future of the Automobile. Scribner, New York. 